\title{
Environmental toxicology and associated human health risks
}

\author{
Muhammad Shahid $^{1} \cdot$ Muhammad Nadeem $^{1} \cdot$ Hafiz Faiq Bakhat $^{1}$
}

Published online: 25 August 2020

(C) Springer-Verlag GmbH Germany, part of Springer Nature 2020

\section{Introduction}

Ecosystem toxicology by anthropogenic activities is a diverse and serious issue confronting society, scientists, and regulatory authorities worldwide. Recently, the world has witnessed rapid and uneven industrial and technological developments accompanied with non-judicial and un-sustainable use of nonrenewable resources. Resultantly, several products and byproducts of the activities have become pollutants consequently affecting the environmental health and integrity (Sarwar et al. 2019; Shahid et al. 2017b). The impacts associated with these pollutants range from local to regional and transboundaries as the contaminants are transported, circulated, and accumulated in different environmental compartments (Khalid et al. 2020a; Natasha et al. 2020c; Shahid et al. 2014, 2017c). As a result, ecosystem contamination has become a widespread global concern.

The environmental toxicology by various pollutants, especially trace elements, has raised many hazards to human, plants, and ecological health (Natasha et al. 2020d; Shabbir et al. 2020; Shahid et al. 2020b). A number of these pollutants are highly persistent, build up in human tissues, and are capable of inducing various human health disorders (Antoniadis et al. 2019; Shahid et al. 2020a). When humans are exposed to supra-optimal levels of these pollutants, they induce or contribute to a number of diseases such as cancer, reproductive disorders, respiratory diseases, and immune system injuries. Consequently, the noxious effects of hazardous pollutants have appeared as substantial scientific and social challenges to produce pollutant-free food.

It is always precarious to assess the pollutant-mediated human health effects as there exist diverse and complex

Responsible editor: Philippe Garrigues

Muhammad Shahid

muhammadshahid@ciitvehari.edu.pk

1 Department of Environmental Sciences, COMSATS University Islamabad, Vehari Campus, Vehari 61100, Pakistan pathways by which human may get exposed to such pollutants (Amen et al. 2020; Antoniadis et al. 2019; Shah et al. 2020; Shahid et al. 2012). Human exposure to these pollutants may be through inhaling, ingesting/absorbing from atmosphere, food, soil, and water in many types of settings. Uptake and accumulation of pollutants in edible plant tissues has been reported a major pathway of human exposure. Numerous recent studies have traced the possible pathways of soil-planthuman transfer of pollutants and associated toxic effects (Natasha et al. 2020a; Shahid et al. 2017a). Segments of the populations such as the elderly, children, minorities, chronically ill, and the poor may be at the top vulnerability to harmful risks associated with environmental toxicology. Likewise, risk assessment has become exceedingly topical, especially in marketable edibles produced by urban and peri-urban agriculture (Rafiq et al. 2017; Shamshad et al. 2018). Risk assessment indices predict probable routes and levels of pollutant's exposure to human, and thereby assist to evade the health hazards by making and implementing timely decisions/policies/managements (Natasha et al. 2020e; Shahid et al. 2018).

The abovementioned human and ecological health hazards mediated by various pollutants imply the importance of a clean and safe environment, which has become a top issue in modern science. Nowadays, people have become more aware of the human and ecological consequences of pollutants, and demand a more balanced and environmentally sustainable development. Therefore, environmental conservation and sustainable development are also high on the global agenda and are highly interconnected. This implies how important it is to promote the advancement of environmentally sustainable approaches to assess, monitor, and manage hazardous pollutants. A healthy collaboration among researchers, scientists, citizens, and law-makers is therefore vital for integrated environmentally sustainable development.

Under the abovementioned perspective, this special issue "ESCON-2019" focused on environmental toxicology and health as well as the possible human exposures to pollutants. This issue contains a collection of important manuscripts from the international conference on "Environmental Toxicology and Health" held in February 2019 at COMSATS University 
Islamabad, Vehari, Pakistan. These manuscripts present multidisciplinary methodologies to cope with the ongoing local/ regional/global environmental problems allied with environmental toxicology, human health, and environmentally sustainable development.

\section{Manuscripts published in SI of ESCON-2019}

A study by Natasha et al. (2020b) reported the accumulation of arsenic (As) and lead $(\mathrm{Pb})$ by spinach after foliar applications. Lead mainly sequestered in spinach leaves while As was transferred towards the root tissues. Both the trace elements affected photosynthetic apparatus and other pigment contents and plant growth, $\mathrm{Pb}$ being less toxic than As. The authors reported normal production of reactive radicals (ROS) and no harm to lipid membranes. Nevertheless, an increase in the activities of antioxidative enzymes was recorded. The health risk induces revealed possible carcinogenic effects by both $\mathrm{Pb}$ and As, while non-carcinogenic effects (hazard quotient $>1$ ) only by As in children. Authors proposed continuous monitoring of these trace elements in the atmosphere to ensure the food safety and consequently human health.

Using a soil culture experiment, Bakhat et al. (2020) evaluated lithium (Li) uptake by spinach and associated physiological variations under various $\mathrm{Li}$ applied levels $(0$ $80 \mathrm{mg} \mathrm{kg}^{-1}$ soil). Higher levels of Li (40-80 mg kg${ }^{-1}$ soil) enhanced spinach chlorophyll contents but decreased calcium and potassium uptake by spinach. Furthermore, increasing $\mathrm{Li}$ levels in soil caused an upregulation of antioxidant enzymes in the spinach leaves. The authors anticipated that Li mainly accumulated in spinach leaves but did not show any visual phytotoxic symptom. The author recommended that soil analysis especially in urban and peri-urban areas is critical to avoid the build-up of $\mathrm{Li}$ in leafy vegetables to avoid human exposure to the contaminant.

Manzoor et al. (2020) investigated the lead (Pb) phytoremediation potential of Stigmatocarpum criniflorum and Pelargonium $\times$ hortorum. Both the plants were exposed for 3 weeks to $\mathrm{Pb}$-contaminated soils (500-2000 $\mathrm{mg} \mathrm{kg}^{-1}$ ). $P$. hortorum showed a better ability to remediate $\mathrm{Pb}$ contaminated soil than $S$. criniflorum by mediating twotimes higher bioavailable $\mathrm{Pb}$ fraction in rhizosphere (for $2000 \mathrm{mg} \mathrm{kg}^{-1} \mathrm{~Pb}$ ). Overall, a higher $\mathrm{Pb}$ accumulation per plant was recorded for $P$. hortorum compared with $S$. criniflorum. Therefore, the authors recommended $P$. hortorum for remediation of $\mathrm{Pb}$-polluted soils.

Khalid et al. (2020b) collected a total of 129 groundwater samples from Vehari District, Pakistan, and analyzed trace elements levels (copper, lead, nickel, cadmium, chromium, manganese, zinc, and iron). The groundwater levels of $\mathrm{Cd}$ (68\%), $\mathrm{Pb}(93 \%)$, and $\mathrm{Fe}(100 \%)$ were found above their threshold values recommended by WHO. In addition, majority of groundwater samples were found unfit for drinking purpose due to non-compliance with physicochemical parameters such as alkalinity, major cation contents, and chloride. Due to high levels of some trace elements in groundwater, especially $\mathrm{Cd}$, it can potentially induce carcinogenic risks (Cd cancer risk value ranged 0.0007-0.03). Similarly, $\mathrm{Pb}$ showed a possible non-carcinogenic risk due to its mean hazard quotient value $>1$. The authors proposed an urgent need to create mass awareness about the health effects of trace element exposure and planning for the remediation/riskmitigation strategies.

Riaz et al. (2020) collected sewage sludge samples from sewage treatment plants of five different cities of Pakistan and explored their potential and associated risks, if directly applied to agricultural soils, using chemical fractionation techniques. Based on the levels of nutrients and heavy metals $(\mathrm{Cd}, \mathrm{Cr}, \mathrm{Fe}$, $\mathrm{Mn}, \mathrm{Ni}$, and $\mathrm{Zn}$ ), physicochemical properties, and risk assessment codes, the authors made the following recommendations for their possible use in the agricultural sector: (i) Kasur sewage sludge should not be used, (ii) NUST wastewater treatment plant and Water and Sanitation Agency sewage sludge, Islamabad, can be applied at low rates, and (iii) I-9 Sector wastewater treatment plant, Islamabad, Coca-Cola sewage sludge, and Nestle wastewater treatment plant can directly be used owing to minimum risks associated with the waste.

Using a pot experiment, Sardar et al. (2020) determined the suitability of using alone and combined applications of groundwater $(\mathrm{GW})$, freshwater $(\mathrm{FW})$, and sewage water (SW) for spinach production. Results showed that growing spinach decreased trace element level in post-harvest soil samples (As (-0.8\%), $\mathrm{Cr}(-6.2 \%), \mathrm{Fe}(-9.2 \%), \mathrm{Mn}(-13 \%), \mathrm{Zn}$ $(-15 \%)$, Ni $(-16 \%), \mathrm{Pb}(-19 \%), \mathrm{Cu}(-20 \%)$, and $\mathrm{Cd}(-$ $38 \%)$ ) most probably due to their uptake by spinach. The combined application of SW, GW, and FW caused a higher build-up of heavy metal(loid)s (As, $\mathrm{Cr}, \mathrm{Cd}, \mathrm{Fe}, \mathrm{Mn}, \mathrm{Cu}, \mathrm{Ni}$, $\mathrm{Pb}$, and $\mathrm{Zn}$ ) in spinach leaves compared with the alone treatments. Almost all the treatments caused oxidative stress in spinach by provoking lipid peroxidation, especially for GW and FW treatments due to higher trace element accumulation. Irrigation with these waters also anticipated possible noncarcinogenic risks $(\mathrm{HI}>1)$ and carcinogenic risks $(\mathrm{CR}>$ 0.0001). The authors, therefore, suggested the need to monitor irrigation water quality to avoid potential health hazards.

Using a pot experiment, Mushtaq et al. (2020) evaluated the accumulation and tolerance potential of Catharanthus roseus (L.) concerning Bacillus cereus and organic amendments. Results showed that $B$. cereus improved the uptake of $\mathrm{Cr}, \mathrm{Cu}$, and $\mathrm{Cd}$ by $C$. roseus. However, $\mathrm{Ni}$ and $\mathrm{Pb}$ concentrations were highest for control treatment (without strain). On the contrary, the application of organic amendments increased biomass production than controls, while a decrease in trace element uptake by plants was recorded. The authors recommended microbial-facilitated phytoremediation of trace 
elements, while organic amendments mainly enhance plant growth in the presence of trace elements.

Zhu et al. (2020) assessed the environmental performances of 30 Chinese provinces from 2006 to 2015 using a commonweights DEA model. The results elucidated a big gap in regional environmental efficiencies, because the environmental condition of central and western regions is worse than the eastern and northeastern regions. The BMPI analysis revealed no improvement in environmental performances during the 11th and 12th FYPs, showing a big difference in the western region, due to its huge development potential. The authors also proposed some recommendations to improve the environmental performances of various regions in China.

Hussain et al. (2020) used GIS tools to perceive the pattern of NDVI, NDBI, and LULC change in LodhranPakistan using Landsat images of the last 4 decades. About $47 \%$ of farmers perceived high variations in the planting season, temperature, and precipitation in the recent past. There was a $4.3 \%$ increase in building area between 1977 and 2017. The author revealed that the conversion of bare soil into vegetation and built-up areas was the major change during the last 4 decades. Results proposed that the district is facing low rainfall, a decrease in irrigation water, and a rise in temperature.

Iftikhar et al. (2020) synthesized a number of metal-doped $\mathrm{TiO}_{2}$ nanoparticles and assessed their efficiency to photodegrade against some textile contaminants. The screening method proved the highest photocatalytic degradation potential of Fe-1-T-3 with a complete RY145 removal within $80 \mathrm{~min}$ of irradiation. The authors proposed the possible use of $\mathrm{TiO}_{2}$ nanoparticles to remediate textile contaminants.

Sajjad et al. (2020) explored the switching intention of Chinese people towards electric vehicle from motorized vehicle. Results elucidated mooring being the most significant factor followed by the normative environment from pull factors and environmental quality from push factors. The influence of alternative attractiveness remained weak and insignificant, while the effect of the regulative environment was found weak and significant. The switching intentions of Chinese people clearly and significantly explained their green behavior to sustain the environment.

Waleed et al. (2020) explored the irrigation potential sites in Khyber District, Pakistan. The authors used GIS-based multi-criteria analysis and focused on parameters such as topography, soil texture, land cover, and perennial rivers and dams. Results identified various potential land areas for irrigated farming which were classified into three groups as follows: highly suitable to irrigation which covers $26 \%$ of total area $\left(678 \mathrm{~km}^{2}\right)$; moderately suitable which represented $40 \%$ of total area $\left(1044 \mathrm{~km}^{2}\right)$; and least suitable for irrigation which is $27 \%$ of total area $\left(698 \mathrm{~km}^{2}\right)$. Similarly, $7 \%$ of the total area $\left(204 \mathrm{~km}^{2}\right)$ was not suitable for irrigated agriculture as it contained barren rocks.
Neelab et al. (2020) determined the residues of three selected pesticides (carbendazim (CRB), difenoconazole (DFN), and chlorpyrifos (CPF)) in Prunus persica (L.) samples collected from Swat territory. Results reported the presence of all three pesticides in P. persica samples. The residues of DFN and CPF were higher compared with MRLs. Moreover, $P$. persica treatment with $10 \% \mathrm{CH}_{3} \mathrm{COOH}$ resulted in the highest decrease of CPF, DFN, and CRB residues $(86 \%$, $97 \%$, and $89 \%$, respectively) than $10 \% \mathrm{NaCl}$ and $10 \% \mathrm{NaOH}$.

Amjad et al. (2020) assessed the pyrethroid residues in 180 samples of okra and eggplant collected from the peri-urban agriculture of Gujranwala, Multan, and Faisalabad. Results revealed that $32 \%$ of the samples contained detectable residues of pyrethroid, while $6 \%$ of the samples had residues above maximum residual limit (MRL). Conclusively, higher pyrethroid residues were detected in Multan than Faisalabad, and Gujranwala. Overall, despite some samples exceeded MRLs, their nontoxic ingestion limit was observed.

Zamin et al. (2020) conducted mowing tests on Aeluropus lagopoides ecotypes during the years 2014-2016 under desert climatic condition. Mowing treatments (such as cut back at 1-, 2-, 3-, 4-, and 5-cm high) were conducted on 50 ecotypes of A. lagopoides. Results revealed significant variations among different ecotypes for various agronomic parameters such as canopy stiffness, internode length, fresh and dry weights of clippings, number of leaves, and ground cover. Overall, better performance of all the A. lagopoides ecotypes was noticed at the standard mowing heights of 3 and $4 \mathrm{~cm}$. Five ecotypes (FA5, RUADA1, RUDA7, RUDA2, and RA3) exhibited the best performance under applied mowing shock.

Using a questionnaire method, Zhang et al. (2020) explored the sustainability of small-scale agriculture (SA) in terms of labor productivity (LP) in Hani terraced region, China. Results showed that hybrid rice cropping generates a low income (3854.5 yuan) to peasant households compared with non-farm jobs $(44,665.8$ yuan). These households invest a major portion of their labors for non-farm jobs (522 person/days) and a low part on growing hybrid rice (34.23 person/days). The authors concluded that, for a household, the LP of hybrid rice cropping is about 1.3-fold compared with non-farm jobs. The result revealed a greater return of SA labor investments compared with non-farm jobs in Hani terraced region.

Saleem et al. (2020) traced the land cover and land use pattern supervised classifications. They mapped four classes including barren lands, built-up, water bodies, and vegetation. Results revealed lower temperatures in areas having higher vegetation covers, while higher temperatures were reported in the built-up areas and barren lands. In Lahore district, about $2{ }^{\circ} \mathrm{C}$ increase in surface temperature was noted in the last 20 years. Similarly, Multan and Faisalabad districts showed an increase, respectively, of $2.4{ }^{\circ} \mathrm{C}$ and $2.2{ }^{\circ} \mathrm{C}$ of surface temperatures during the last 19 years. The authors recommended the importance of appropriate planning for the sustainable urban management. 


\section{References}

Amen R, Bashir H, Bibi I, Shaheen SM, Niazi NK, Shahid M, Hussain MM, Antoniadis V, Shakoor MB, Al-Solaimani SG, Wang H, Bundschuh J, Rinklebe J (2020) A critical review on arsenic removal from water using biochar-based sorbents: the significance of modification and redox reactions. Chem Eng J 396:125195

Amjad A, Randhawa MA, Javed MS, Muhammad Z, Ashraf M, Ahmad Z, Murtaza S (2020) Dietary intake assessment of pyrethroid residues from okra and eggplant grown in peri-urban areas of Punjab, Pakistan. Environ Sci Pollut Res Int

Antoniadis V, Shaheen S, Levizou E, Shahid M, Niazi N, Vithanage M, Ok Y, Bolan N, Rinklebe J (2019) A critical prospective analysis of the potential toxicity of trace element regulation limits in soils worldwide: are they protective concerning health risk assessment? - a review. Environ Int 127:819-847

Bakhat HF, Rasul K, Farooq ABU, Zia Z, Natasha FS, Abbas S, Shah GM, Rabbani F, Hammad HM (2020) Growth and physiological response of spinach to various lithium concentrations in soil. Environ Sci Pollut Res Int

Hussain S, Mubeen M, Ahmad A, Akram W, Hammad HM, Ali M, Masood N, Amin A, Farid HU, Sultana SR, Fahad S, Wang D, Nasim W (2020) Using GIS tools to detect the land use/land cover changes during forty years in Lodhran District of Pakistan. Environ Sci Pollut Res Int

Iftikhar A, Khan MS, Rashid U, Mahmood Q, Zafar H, Bilal M, Riaz N (2020) Influence of metallic species for efficient photocatalytic water disinfection: bactericidal mechanism of in vitro results using docking simulation. Environ Sci Pollut Res Int

Khalid S, Shahid M, Murtaza B, Bibi I, Natasha NM, Niazi N (2020a) A critical review of different factors governing the fate of pesticides in soil under biochar application. Sci Total Environ 711:134645

Khalid S, Shahid M, Natasha SA, Saeed F, Ali M, Qaisrani S, Dumat C (2020b) Heavy metal contamination and exposure risk assessment via drinking groundwater in Vehari-Pakistan. Environ Sci Pollut Res Int

Manzoor M, Gul I, Manzoor A, Kamboh UR, Hina K, Kallerhoff J, Arshad M (2020) Lead availability and phytoextraction in the rhizosphere of Pelargonium species. Environ Sci Pollut Res Int

Mushtaq MU, Iqbal A, Nawaz I, Mirza CR, Yousaf S, Farooq G, Ali MA, Khan AHA, Iqbal M (2020) Enhanced uptake of $\mathrm{Cd}, \mathrm{Cr}$, and $\mathrm{Cu}$ in Catharanthus roseus (L.) G. Don by Bacillus cereus: application of moss and compost to reduce metal availability. Environ Sci Pollut Res Int

Natasha, Shahid M, Farooq ABU, Rabbani F, Khalid S, Dumat C (2020a) Risk assessment and biophysiochemical responses of spinach to foliar application of lead oxide nanoparticles: a multivariate analysis. Chemosphere 245:125605

Natasha, Shahid M, Khalid S (2020b) Foliar application of lead and arsenic solutions to Spinacia oleracea: biophysiochemical analysis and risk assessment. Environ Sci Pollut Res Int

Natasha, Shahid M, Khalid S, Bibi I, Bundschuh J, Niazi N, Dumat C (2020c) A critical review of mercury speciation, bioavailability, toxicity and detoxification in soil-plant environment: ecotoxicology and health risk assessment. Sci Total Environ 711:134749

Natasha, Shahid M, Saleem M, Anwar H, Khalid S, Tariq TZ, Murtaza B, Amjad M, Naeem MA (2020d) A multivariate analysis of comparative effects of heavy metals on cellular biomarkers of phytoremediation using Brassica oleracea. Int J Phytoremediation 22:617-627

Natasha, Shahid M, Sardar A, Anwar H, Khalid S, Shah SH, Shah AH, Bilal M (2020e) Effect of co-application of wastewater and freshwater on the physiological properties and trace elements content in Raphanus sativus: soil contamination and human health. Environ Geochem Health
Neelab, Asi MR, Kali S, Riaz MA, Waseem A, Iqbal MM, Ahmad N, Iqbal M, Masood N, Zafar MI (2020) Comparative efficacy of mitigation techniques for the detoxification of Prunus persica (L.) from selected pesticide residues. Environ Sci Pollut Res Int

Rafiq M, Shahid M, Abbas G, Shamshad S, Khalid S, Niazi NK, Dumat C (2017) Comparative effect of calcium and EDTA on arsenic uptake and physiological attributes of Pisum sativum. Int $\mathrm{J}$ Phytoremediation 19:662-669

Riaz U, Murtaza G, Saifullah FM, Aziz H, Qadir AA, Mehdi SM, Qazi MA (2020) Chemical fractionation and risk assessment of trace elements in sewage sludge generated from various states of Pakistan. Environ Sci Pollut Res Int

Sajjad A, Asmi F, Chu J, Anwar MA (2020) Environmental concerns and switching toward electric vehicles: geographic and institutional perspectives. Environ Sci Pollut Res Int

Saleem MS, Ahmad SR, Shafiq-Ur-Rehman, Javed MA (2020) Impact assessment of urban development patterns on land surface temperature by using remote sensing techniques: a case study of Lahore, Faisalabad and Multan district. Environ Sci Pollut Res

Sardar A, Shahid M, Natasha KS, Anwar H, Tahir M, Shah G, Mubeen M (2020) Risk assessment of heavy metal (loid) s via Spinacia oleracea ingestion after sewage water irrigation practices in Vehari District. Environ Sci Pollut Res Int

Sarwar T, Shahid M, Khalid S, Shah AH, Ahmad N, Naeem MA, ul Haq Z, Murtaza B, Bakhat HF (2019) Quantification and risk assessment of heavy metal build-up in soil-plant system after irrigation with untreated city wastewater in Vehari, Pakistan. Environ Geochem Health

Shabbir Z, Sardar A, Shabbir A, Abbas G, Shamshad S, Khalid S, Natasha MG, Dumat C, Shahid M (2020) Copper uptake, essentiality, toxicity, detoxification and risk assessment in soil-plant environment. Chemosphere 259:127436

Shah AH, Shahid M, Khalid S, Shabbir Z, Bakhat HF, Murtaza B, Farooq A, Akram M, Shah GM, Nasim W (2020) Assessment of arsenic exposure by drinking well water and associated carcinogenic risk in peri-urban areas of Vehari, Pakistan. Environ Geochem Health 42: 121-133

Shahid M, Pinelli E, Dumat C (2012) Review of Pb availability and toxicity to plants in relation with metal speciation; role of synthetic and natural organic ligands. J Hazard Mater 219:1-12

Shahid M, Pourrut B, Dumat C, Nadeem M, Aslam M, Pinelli E (2014) Heavy-metal-induced reactive oxygen species: phytotoxicity and physicochemical changes in plants, reviews of environmental contamination and toxicology volume 232. Springer, pp 1-44

Shahid M, Dumat C, Khalid S, Niazi NK, Antunes PM (2017a) Cadmium bioavailability, uptake, toxicity and detoxification in soil-plant system. Rev Environ Contam Toxicol 241:73-137

Shahid M, Dumat C, Khalid S, Schreck E, Xiong T, Niazi NK (2017b) Foliar heavy metal uptake, toxicity and detoxification in plants: a comparison of foliar and root metal uptake. J Hazard Mater 325:3658

Shahid M, Shamshad S, Rafiq M, Khalid S, Bibi I, Niazi NK, Dumat C, Rashid MI (2017c) Chromium speciation, bioavailability, uptake, toxicity and detoxification in soil-plant system: a review. Chemosphere 178:513-533

Shahid M, Niazi NK, Dumat C, Naidu R, Khalid S, Rahman MM, Bibi I (2018) A meta-analysis of the distribution, sources and health risks of arsenic-contaminated groundwater in Pakistan. Environ Pollut 242:307-319

Shahid M, Natasha DC, Niazi N, Xiong T, Farooq A, Khalid S (2020a) Ecotoxicology of heavy metal (loid) enriched particulate matter: foliar accumulation by plants and health impacts. Rev Environ Contam Toxicol

Shahid M, Niazi NK, Rinklebe J, Bundschuh J, Dumat C, Pinelli E (2020b) Trace elements-induced phytohormesis: a critical review 
and mechanistic interpretation. Crit Rev Environ Sci Technol 50: 1984-2015

Shamshad S, Shahid M, Rafiq M, Khalid S, Dumat C, Sabir M, Murtaza B, Farooq ABU, Shah NS (2018) Effect of organic amendments on cadmium stress to pea: a multivariate comparison of germinating vs young seedlings and younger vs older leaves. Ecotoxicol Environ Saf 151:91-97

Waleed M, Ahmad SR, Javed MA, Samiullah S (2020) Identification of irrigation potential areas, using multi-criteria analysis in Khyber District, Pakistan. Environ Sci Pollut Res Int

Zamin M, Fahad S, Khattak AM, Adnan M, Wahid F, Raza A, Wang D, Saud S, Noor M, Bakhat HF, Mubeen M, Hammad HM, Soliman MH, Elkelish AA, Riaz M, Nasim W (2020) Developing the first halophytic turfgrasses for the urban landscape from native Arabian desert grass. Environ Sci Pollut Res Int

Zhang Y, He L, Liu L, Min Q (2020) Labor productivity of small-scale agriculture and its influence on agricultural landscape conservation in mountainous areas in China: a case study of rice farming in Hani terraced region. Environ Sci Pollut Res Int

Zhu W, Zhu Y, Yu Y (2020) China's regional environmental efficiency evaluation: a dynamic analysis with biennial Malmquist productivity index based on common weights. Environ Sci Pollut Res Int

Publisher's note Springer Nature remains neutral with regard to jurisdictional claims in published maps and institutional affiliations.

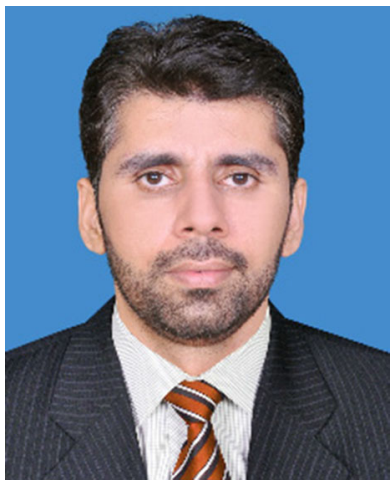

Dr. Muhammad Shahid, Ph.D. from the University of ToulouseFrance, is an Associate Professor at the Department of Environmental Sciences, COMSATS University Islamabad, Vehari Campus. His key areas of research include trace element biogeochemical behavior in the soil-plant-human systems, wastewater and drinking water analysis/treatment, plant stress physiology, remediation of trace element polluted sites, and health risk assessment. Till date, he has published about 120 research articles, 2 textbooks, and 18 book chapters. $\mathrm{He}$ is also PI or Co-PI of 20 research projects sponsored by various national and international funding agencies.

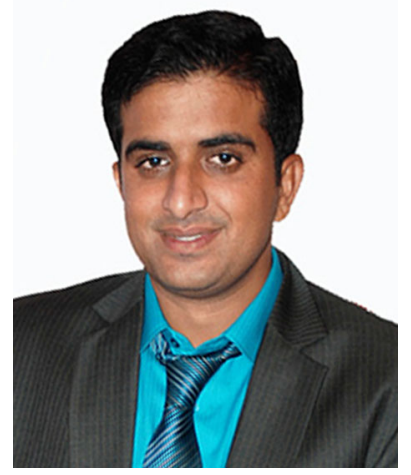

Dr. Muhammad Nadeem is working as an Assistant Professor in the Department of Environmental Sciences, COMSATS University Islamabad, Vehari Campus. He obtained his Ph.D. degree in Food Science and Technology from the University of Agriculture, Faisalabad, Pakistan. His key areas of research are food safety and toxicology and environmental health vs human health. Currently, he is working with many local and international research groups to explore the relationship between food, environment, and public health. He has a good number of research publications ( 81 numbers) in reputed journals along with book chapters ( 3 numbers) and conference proceedings (12 numbers) to his credit.

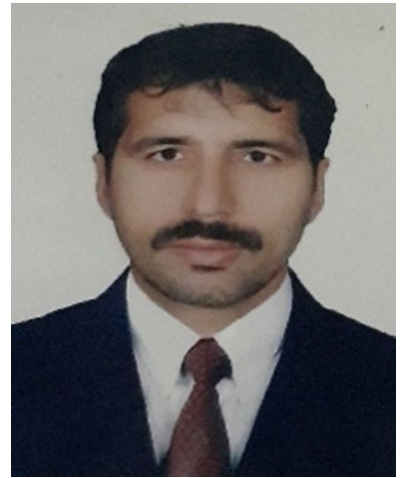

Dr. Hafiz Faiq Bakhat (Assistant Professor, Department of Environmental Sciences COMSATS University Islamabad, Vehari Campus) did his Ph.D. from the Justus Liebig University Giessen-Germany. His area of research specifies plant nutrition and plant eco-physiology. His focus of research lies to elucidate the effect of mineral element and their essential/beneficial/toxic role in plant physiology and bio-chemistry. His scholarly contribution to various national and international journals includes 30 articles and 3 book chapters. Additionally, he is actively engaged with the under-graduate and graduate students for their research thesis and projects. 